\title{
Improved cloud radio access network based fair network model in internet pricing
}

\author{
Indrawati, Fitri Maya Puspita, Desta Wahyuni, Evi Yuliza, Oki Dwipurwani \\ Department of Mathematics, Faculty of Mathematics and Natural Sciences, Sriwijaya University, Indonesia
}

\begin{tabular}{|c|c|}
\hline Article Info & ABSTRACT \\
\hline Article history: & In this study, the pricing scheme that will be formed is a model from the \\
\hline Received Mar 15, 2020 & RAN) and fair network management models. This model combines the benefits \\
\hline Revised Dec 9, 2020 & of internet service provider (ISP) and service quality (QoS) obtained by internet \\
\hline Accepted Jan 14, 2021 & $\begin{array}{l}\text { users, one of which is fair network factors. The model used is a nonlinear } \\
\text { equation and is solved by the LINGO } 13.0 \text { program to get the optimal solution. }\end{array}$ \\
\hline Keywords: & $\begin{array}{l}\text { The results show that the pricing scheme with regard to service quality } \\
\text { generates maximum revenue for ISPs. Based on the improved C-RAN model }\end{array}$ \\
\hline $\begin{array}{l}\text { C-RAN } \\
\text { Fair network }\end{array}$ & $\begin{array}{l}\text { that are classified into } 2 \text { cases, the optimal results in the improved model, the } \\
\text { optimal value is found in the pricing scheme in case } 1 \text { of by conducting } \\
\text { numerical computation using hotspot traffic from local server. }\end{array}$ \\
\hline
\end{tabular}

Quality of service
This is an open access article under the CC BY-SA license. \begin{abstract}
previous research model involving model of cloud-radio access network $(\mathrm{C}$ RAN) and fair network management models. This model combines the benefits equation and is solved by the LINGO 13.0 program to get the optimal solution. The results show that the pricing scheme with regard to service quality that are classified into 2 cases, the optimal results in the improved model, the numerical computation using hotspot traffic from local server.
\end{abstract}

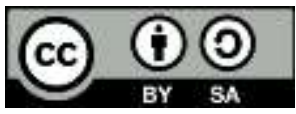

\section{Corresponding Author:}

Fitri Maya Puspita

Department of Mathematics

Faculty of Mathematics and Natural Sciences, Sriwijaya University

Jln. Raya Palembang-Prabumulih, KM 32 Indralaya Ogan Ilir 30662 South Sumatera, Indonesia

Email: pipitmac140201@gmail.com

\section{INTRODUCTION}

Internet now a days is every human needs. Internet service providers (ISPs) [1], [2] must attempt the best way to promote their service to encourage customers to use it. Some strategies conducting by ISPs are to minimize costs and maximize profits by designing the customization, bundling, and versioning [3]. The increasing internet users, the greeter the demand for quality of services (QoS) [4]-[8] that is better and different with others. Utility function [5], [9]-[10] as measurement for consumer's satisfaction should also be considered by ISP in determining the pricing scheme. Using utility function appropriately helps ISP in obtaining the right choice in maximizing the profit [11], [12].

Previous research on internet pricing based mathematical programming problem model was initially put forward in optimizing-based networks [13]-[15]. The models begin from pricing scheme-based wired network, then for wireless network, involving bundling strategy and utility function. Cloud-radio access network (C-RAN) scheme is a scheme based on long term evolution (LTE) management [16], [17] that works under a wireless network cloud. C-RAN is a new enhancement in digital technology. Cloud radio computing or C-RAN is part of the cloud [18]-[20] where C-RAN focuses on sending data using a base station that are centralized and then data are connected to a cellular antenna and forward the data to the radio antenna tower.

Fair network management [21]-[23] is one issue dealing with consumption of bandwidth in networks, nowadays. How to divide appropriate networks fairly among users [24] are still big issue for ISP to conduct. One instance when dealing with network utility is addressing multiple resources allocation [9], [25], other is by conduction active queue management (AQM) [24], [26], [27] for increasing network efficiency. 
It is a necessity to develop improved model C-RAN-based fair network that is enable to enhance the pricing scheme based C-RAN proposed by ISP in fair networks. Scarce research that focus on determining model as mathematical programming model. The mathematical programming model has some advantages due to its simplicity in looking for solution optimally and ability to identify the parameter and decision variables clearly in the model [28]. Based on criteria stated before, the C-RAN based fair network will be developed.

\section{RESEARCH METHOD}

The research starts from searching for material and studying material related to C-RAN and fair network models from various literatures. Then, the bandwidth data obtained is processed and divided into 2 categories, namely data during peak hours and data during off-peak hours, and then the data is classified based on average bandwidth usage per day of 10,000 kbps. The modified C-RAN-based fair network model will be solved optimally using the LINGO program. Parameters and variables are used to solve optimization problems based on the model being formed.

The idea of designing the improved model of C-RAN is explained in flowchart as Figure 1 displayed as follows. C-RAN model will be designed by utilizing the fair network that assists users in applying network fairly. The new improved model is designed to give benefit to ISP by regulating fair and proper network based on C-RAN. Improved model will be tested numerically for local data Hotspot 3 and Hotspot 4 in Public University in Palembang.

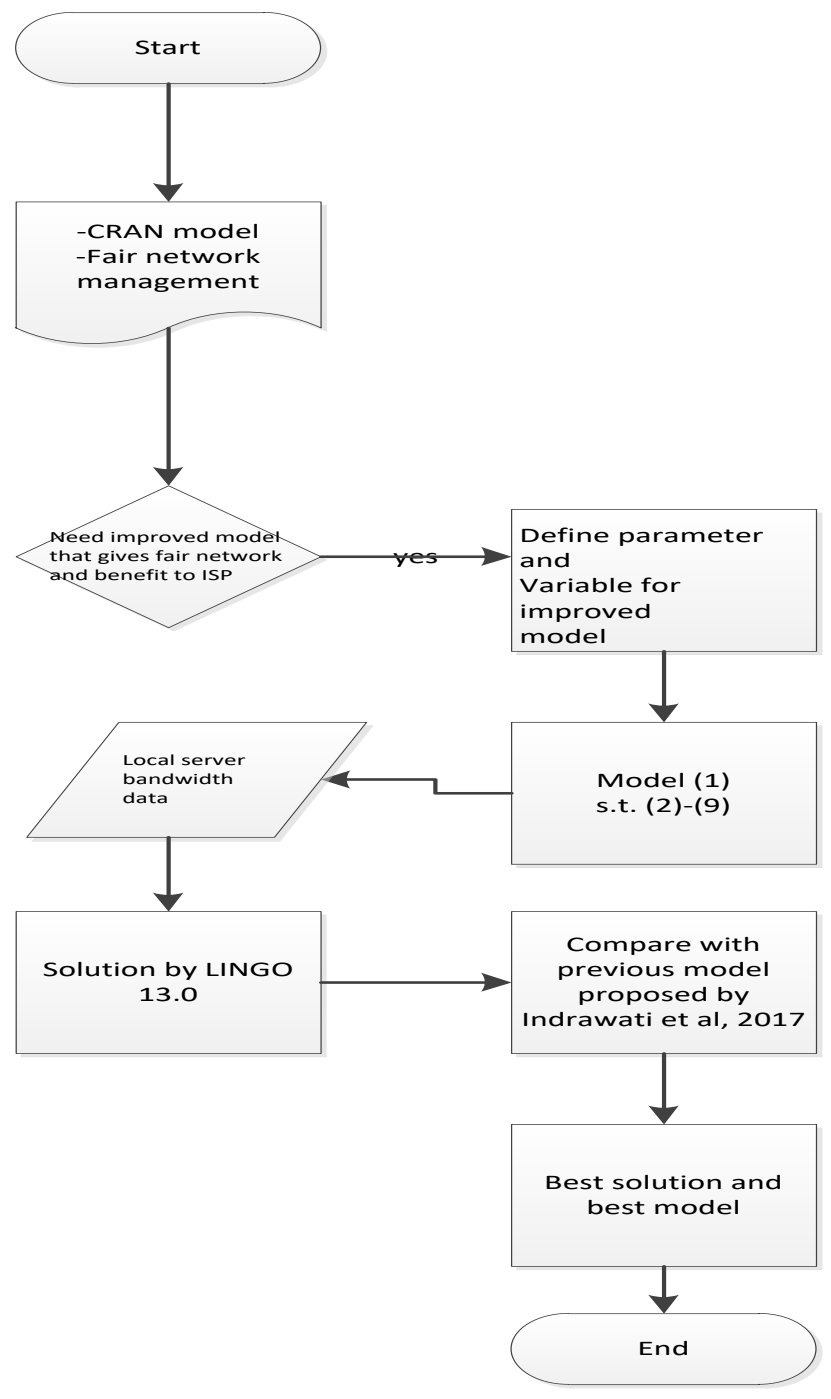

Figure 1. Flowchart of designing new improved C-RAN based on fair network management 


\section{RESULTS AND ANALYSIS}

First step is defining the parameters and variables. Parameters and variables set up based on previous model proposed by [29] followed by fair network proposed by [30]. Table 1 is data processed that is obtained in one of local server. Tables 2-3 explain the parameters and variables, respectively.

Table 1. Internet use during busy and non busy hours

\begin{tabular}{ccc}
\hline & Use of Hotspot 3 (bytes) & Use of Hotspot 4 (kbps) \\
\hline $\bar{X}=\bar{X}_{1}$ & 7105022.145 & 6938.498188 \\
$\bar{X}_{2}$ & 6976692.176 & 6813.175953 \\
$X_{m}$ & 785924.1665 & 767.5040688 \\
$\bar{Y}=\bar{Y}_{1}$ & 7135022.539 & 6967.795448 \\
$\bar{Y}_{2}$ & 5442395.93 & 5314.839775 \\
$Y_{m}$ & 602.4997223 & 0.588378635 \\
\hline
\end{tabular}

Table 2. The parameters for each improved model

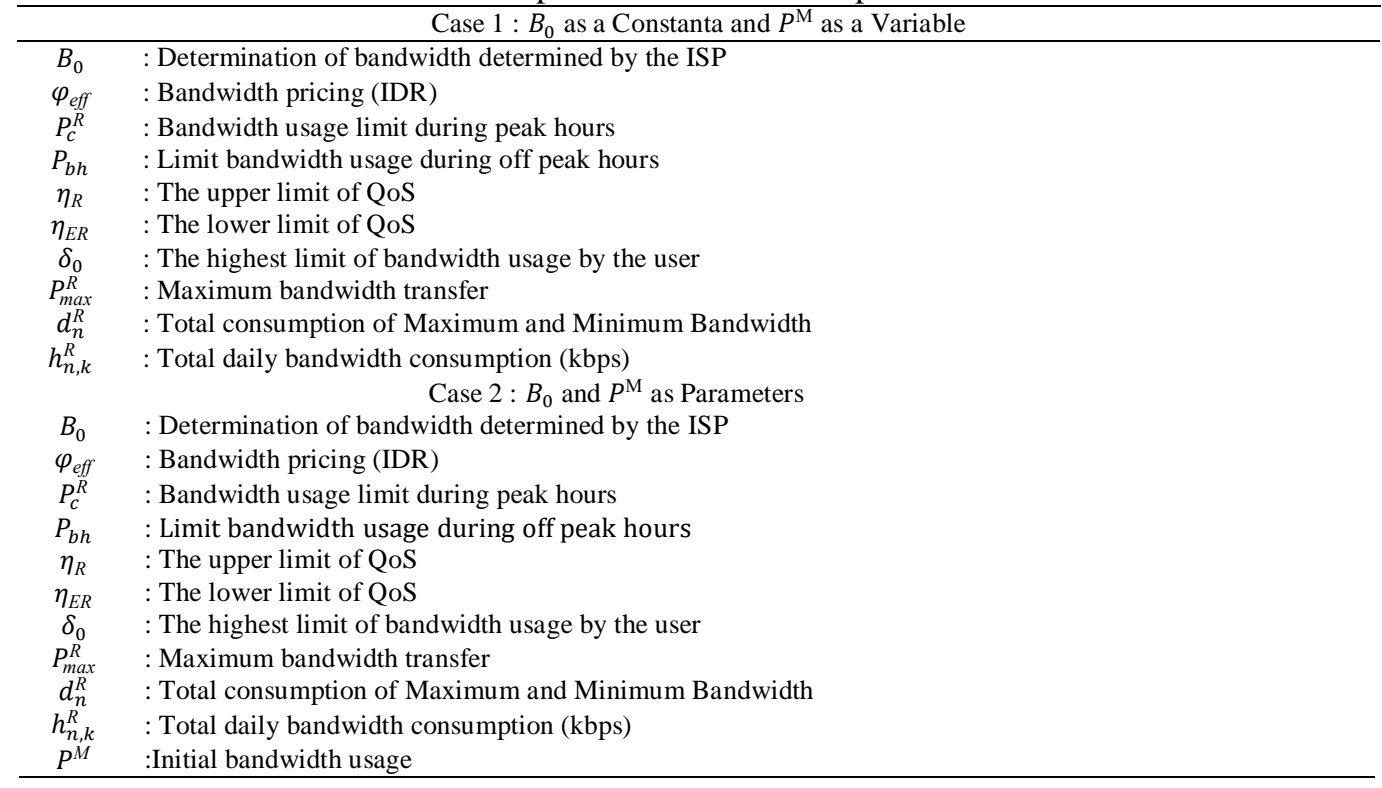

Table 3. Decision variable for each improved model

\begin{tabular}{|c|c|}
\hline \multicolumn{2}{|r|}{ Case $1: B_{0}$ as a Parameter and $P^{\mathrm{M}}$ as a Variable } \\
\hline$a_{n, k}$ & : Resource Block (RB) allocation indicator that has a value of 0 or 1 \\
\hline$p_{n, k}$ & $\begin{array}{l}\text { : Transferring bandwidth from Resource Block (RB) to Remote User } \\
\text { Equipment (RUE) }\end{array}$ \\
\hline$d_{k}^{R 2 M}$ & : Appropriate path loss from Remote Radio Heads (RRH) in Resource Block (RB) \\
\hline$h_{k}^{R 2 M}$ & : Appropriate channel gain from Remote Radio Heads (RRH) on Resource Block (RB) \\
\hline$\stackrel{n}{P^{M}}$ & : Initial bandwidth usage \\
\hline$d_{n}^{M}$ & : Path loss from Resource Block (RB) to Remote User Equipment (RUE) \\
\hline$h_{n, k}^{M}$ & : Channel gain from Resource Block (RB) to Remote User Equipment(RUE) \\
\hline$N_{0}$ & $\begin{array}{l}\text { Bandwidth usage when not hosting } \\
\qquad \text { Case } 2: B_{0} \text { dan } P^{\mathrm{M}} \text { as parameter }\end{array}$ \\
\hline$a_{n, k}$ & : Resource Block (RB) allocation indicator that has a value of 0 or 1 \\
\hline$p_{n, k}$ & $\begin{array}{l}\text { : Transferring bandwidth from Resource Block (RB) to Remote User } \\
\text { Equipment (RUE) }\end{array}$ \\
\hline$d_{k}^{R 2 M}$ & : Appropriate path loss from Remote Radio Heads (RRH) in Resource Block (RB) \\
\hline$h_{k}^{R 2 M}$ & : Appropriate channel gain from Remote Radio Heads (RRH) on Resource Block (RB) \\
\hline$\stackrel{n}{d_{n}^{M}}$ & : Path loss from Resource Block (RB) to Remote User Equipment (RUE) \\
\hline$h_{n, k}^{M}$ & : Channel gain from Resource Block (RB) to Remote User Equipment (RUE) \\
\hline$N_{0}$ & : Bandwidth usage when not hosting \\
\hline
\end{tabular}

Then, our Improved C-RAN based fair network are as follows.

$$
\operatorname{Max} \frac{\sum_{n=1}^{N+M} \sum_{k=1}^{K} a_{n, k} B_{0} \log _{2}\left(1+\sigma_{n, k} p_{n, k}\right)+\left(\sum_{j=1}^{u} x_{j}\right)^{2}}{\varphi_{\mathrm{eff}} \sum_{n=1}^{N+M} \sum_{k=1}^{K} a_{n, k} p_{n, k}+P_{c}^{\mathrm{R}}+P_{\mathrm{bh}}+u \sum_{j=1}^{u} x_{j}^{2}}
$$


Subject to:

$$
\begin{aligned}
& \sum_{n=1}^{N+M} a_{n, k}=1, a_{n, k} \in\{0,1\}, k=2 \\
& \sum_{n=1}^{N} C_{n, k} \geq \eta_{\mathrm{R}}, k \in \Omega_{1} \\
& \sum_{n=N+1}^{N+M} C_{n, k} \geq \eta_{\mathrm{ER}}, k \in \Omega_{2} \\
& \sum_{n=N}^{N+M} a_{n, k} p_{n, k} d_{k}^{\mathrm{R} 2 \mathrm{M}} h_{k}^{\mathrm{R} 2 \mathrm{M}} \leq \delta_{0}, k \in \Omega_{\mathrm{II}} \\
& \sum_{n=1}^{N+M} \sum_{k=1}^{K} a_{n, k} p_{n, k} \leq P_{\max }^{\mathrm{R}}, p_{n, k} \geq 0 \\
& x_{j} \geq C_{j}^{\text {min }}
\end{aligned}
$$

With,

$$
\begin{aligned}
& C_{n, k}=a_{n, k} B_{0} \log _{2}\left(1+\sigma_{n, k} p_{n, k}\right)
\end{aligned}
$$

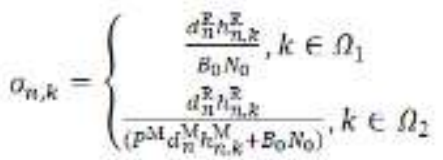

The C-RAN network originally comes from (2)-(6) with added variable of total bandwidth for user $j$, $x_{j}$ as model for fair network. The model then will be solved by optimization tool, LINGO 13.0 to obtain the optimal result for optimal revenue gained by ISP. The original model to be compared then, is the model used by Indrawati et a.l [29] that has objective to maximize $\frac{\sum_{n=1}^{N+M} \sum_{k=1}^{K} a_{n, k} B_{0} \log _{2}\left(1+\sigma_{n, k} p_{n, k}\right)}{\varphi_{e f f} \sum_{n=1}^{N+M} \sum_{k=1}^{K} a_{n, k} p_{n, k}+P_{c}^{R}+P_{b h}}$ with constraint $x_{j} \geq$ $C_{j}{ }^{\min }$. The parameters for original model is presented in Table 4. The solution of original model is presented in Table 5 while in Tables 6-7, the solutions for improved model proposed applied in different data traffic, which are hotspot 3 and hotspot 4.

Table 4. Parameter values used in indrawati et al. [29]

\begin{tabular}{cc}
\hline Parameters & Value $(\mathrm{kbps})$ \\
\hline$\left(B_{0}\right)$ & 5000 \\
$\left(\varphi_{\text {eff }}\right)$ & 500 \\
$\left(P_{c}^{R}\right)$ & 4500 \\
$\left(P_{b h}\right)$ & 4000 \\
$\left(\eta_{\mathrm{R}}\right)$ & 128 \\
$\left(\eta_{\mathrm{ER}}\right)$ & 64 \\
$\left(\delta_{0}\right)$ & 7000 \\
$\left(P_{\max }^{\mathrm{R}}\right)$ & 500 \\
$\left(P_{m}\right)$ & 150 \\
\hline
\end{tabular}

Table 5. Original model solution

\begin{tabular}{ccc}
\hline Solver Status & \multicolumn{3}{c}{ Case } \\
& \multicolumn{3}{c}{ MINLP } \\
\hline Model Class & \multicolumn{2}{c}{ Global Optimal } \\
State & 0.0209997 & 0.0209989 \\
Objective & 0 & 0 \\
Infeasibility & 8 & 131 \\
Iterations & 1.34568 & 150 \\
$P^{M}$ & Branch and Bound & Branch and Bound \\
Solver Type & 0.209997 & 0.0209989 \\
Best Objective & 0 & 0 \\
Steps & 2 & 2 \\
Update Interval & 64 & 64 \\
GMU (K) & 0 & 2 \\
ER (Sec) & & \\
\hline
\end{tabular}

As Table 5 shows, the objective function of original model shows lower value rather than the improved model. It shows us that both improved model shows better results since involving fair network management. All models are in mixed integer nonlinear programming forms, solved using branch and bound solver as LINGO 13.0 informed. Tables 6-7 show the solution in hotspot 3 and hotspot 4, respectively. Both objective value shows the same value. As Table 8 explained, all decision variables from original and improved models are displayed. However, the comparison between the three models is case 1 in an improved model that uses hotspot 4 data traffic to provide better results in terms of objective function value. Therefore, by setting up bandwidth earned and varied the initial bandwidth, ISP yields higher results of profit, which is IDR $1 / \mathrm{kbps}$. 
Table 6. Improved model solutions hotspot 3 Traffic

\begin{tabular}{ccc}
\hline Solver Status & \multicolumn{2}{c}{ Case } \\
\hline Model Class & MINLP & 2 \\
State & \multicolumn{2}{c}{ Global Optimal } \\
Objective & 1 & 1 \\
Infeasibility & 0 & 0 \\
Iterations & 11 & 11 \\
$P^{M}$ & 1.234568 & 150 \\
Solver Type & Branch and Bound & Branch and Bound \\
Best Objective & 1 & 1 \\
Steps & 0 & 0 \\
Update Interval & 2 & 2 \\
GMU (K) & 66 & 66 \\
ER (Sec) & 0 & 0 \\
\hline
\end{tabular}

Table 7. Improved model solutions for hotspot 4 traffic

\begin{tabular}{ccc}
\hline Solver Status & \multicolumn{2}{c}{ Case } \\
\hline Model Class & MINLP & 2 \\
State & \multicolumn{2}{c}{ Global Optimal } \\
Objective & 1 & 1 \\
Infeasibility & 0 & 0 \\
Iterations & 8 & 8 \\
$P^{M}$ & 1.234568 & 150 \\
Solver Type & Branch and Bound & Branch and Bound \\
Best Objective & 1 & 1 \\
Steps & 0 & 0 \\
Update Interval & 2 & 2 \\
GMU (K) & 65 & 66 \\
ER (Sec) & 0 & 0 \\
\hline
\end{tabular}

Table 8. Variable values for the original model, improved hotspot 3 model, and improved hotspot 4 model

\begin{tabular}{|c|c|c|c|c|c|c|}
\hline \multirow[t]{2}{*}{ Solver Status } & \multicolumn{2}{|c|}{ Original Model } & \multicolumn{2}{|c|}{ Value } & \multicolumn{2}{|c|}{ Improved Model for hotspot 4} \\
\hline & Case 1 & Case 2 & Case 1 & Case 2 & Case 1 & Case 2 \\
\hline$a_{11}$ & 0 & 1 & 0 & 0 & 0 & 0 \\
\hline$a_{12}$ & 0 & 0 & 1 & 1 & 0 & 0 \\
\hline$a_{13}$ & 1 & 1 & 1 & 1 & 1 & 1 \\
\hline$a_{21}$ & 0 & 0 & 0 & 0 & 0 & 1 \\
\hline$a_{22}$ & 0 & 0 & 0 & 0 & 0 & 0 \\
\hline$a_{23}$ & 1 & 1 & 1 & 1 & 1 & 1 \\
\hline$a_{33}$ & 1 & 1 & 1 & 1 & 1 & 1 \\
\hline$a_{34}$ & 1 & 1 & 1 & 1 & 1 & 1 \\
\hline$a_{35}$ & 1 & 1 & 1 & 1 & 1 & 1 \\
\hline$a_{36}$ & 1 & 1 & 1 & 1 & 1 & 1 \\
\hline$a_{41}$ & 0 & 0 & 1 & 1 & 1 & 0 \\
\hline$a_{42}$ & 1 & 1 & 0 & 0 & 0 & 1 \\
\hline$a_{43}$ & 1 & 1 & 1 & 1 & 1 & 1 \\
\hline$a_{44}$ & 1 & 1 & 1 & 1 & 1 & 1 \\
\hline$a_{45}$ & 1 & 1 & 1 & 1 & 1 & 1 \\
\hline$a_{46}$ & 1 & 1 & 1 & 1 & 1 & 1 \\
\hline$a_{51}$ & 1 & 0 & 0 & 0 & 0 & 0 \\
\hline$a_{53}$ & 1 & 1 & 1 & 1 & 1 & 1 \\
\hline$a_{54}$ & 1 & 1 & 1 & 1 & 1 & 1 \\
\hline$a_{55}$ & 1 & 1 & 1 & 1 & 1 & 1 \\
\hline$a_{56}$ & 1 & 1 & 1 & 1 & 1 & 1 \\
\hline$a_{62}$ & 0 & 0 & 0 & 0 & 1 & 0 \\
\hline$a_{63}$ & 1 & 1 & 1 & 1 & 1 & 1 \\
\hline$a_{64}$ & 1 & 1 & 1 & 1 & 1 & 1 \\
\hline$a_{65}$ & 1 & 1 & 1 & 1 & 1 & 1 \\
\hline$a_{66}$ & 1 & 1 & 1 & 1 & 1 & 1 \\
\hline$P_{11}$ & 1.234568 & 249.9930 & 1.234568 & 1.234568 & 1.234568 & 1.234568 \\
\hline$P_{12}$ & 1.234568 & 1.234568 & 1.234568 & 376.4537 & 1.234568 & 1.234568 \\
\hline$P_{13}$ & 1.234568 & 1.234568 & 1.234568 & 1.234568 & 1.234568 & 1.234568 \\
\hline$P_{21}$ & 1.234568 & 1.234568 & 1.234568 & 1.234568 & 1.234568 & 268.8341 \\
\hline$P_{22}=P_{23}$ & 1.234568 & 1.234568 & 1.234568 & 1.234568 & 1.234568 & 1.234568 \\
\hline$P_{31}=P_{32}=P_{33}=P_{34}=P_{35}=P_{36}$ & 1.234568 & 1.234568 & 1.234568 & 1.234568 & 1.234568 & 1.234568 \\
\hline$P_{41}$ & 1.234568 & 1.234568 & 1.234568 & 1.234568 & 222.5723 & 1.234568 \\
\hline$P_{42}$ & 249.7102 & 250.0070 & 1.234568 & 1.234568 & 1.234568 & 231.1659 \\
\hline$P_{43}=P_{44}=P_{45}=P_{46}$ & 1.234568 & 1.234568 & 1.234568 & 1.234568 & 1.234568 & 1.234568 \\
\hline$P_{51}$ & 250.2898 & 1.234568 & 250.4597 & 1.234568 & 1.234568 & 1.234568 \\
\hline$P_{52}=P_{53}=P_{54}=P_{55}=P_{56}=P_{61}$ & 1.234568 & 1.234568 & 1.234568 & 1.234568 & 1.234568 & 1.234568 \\
\hline$P_{62}$ & 1.234568 & 1.234568 & 1.234568 & 1.234568 & 277.4277 & 1.234568 \\
\hline$P_{63}$ & 1.234568 & 1.234568 & 1.234568 & 1.234568 & 1.234568 & 1.234568 \\
\hline$P_{64}$ & 1.234568 & 1.234568 & 1.234568 & 1.234568 & 1.234568 & 1.234568 \\
\hline$P_{65}$ & 1.234568 & 1.234568 & 1.234568 & 1.234568 & 1.234568 & 1.234568 \\
\hline$P_{66}$ & 1.234568 & 1.234568 & 1.234568 & 1.234568 & 1.234568 & 1.234568 \\
\hline$B_{0}$ & Parameter & Parameter & Parameter & Parameter & Parameter & Parameter \\
\hline$P^{M}$ & 1.234568 & Parameter & 1.234568 & Parameter & 1.234568 & Parameter \\
\hline$D_{4}^{M}$ & 1.234568 & 1.234568 & 1.234568 & 1.234568 & 1.234568 & 1.234568 \\
\hline$D_{5}^{M}$ & 1.234568 & 1.234568 & 1.234568 & 1.234568 & 1.234568 & 1.234568 \\
\hline$D_{6}^{M}$ & 1.234568 & 1.234568 & 1.234568 & 1.234568 & 1.234568 & 1.234568 \\
\hline$H_{44}^{M}=\ldots=H_{66}^{M}$ & 1.234568 & 1.234568 & 1.234568 & 1.234568 & 1.234568 & 1.234568 \\
\hline$d_{1}^{R 2 M}$ & 1.234568 & 1.234568 & 1.234568 & 1.234568 & 1.234568 & 1.234568 \\
\hline$d_{2}^{R 2 M}=\ldots=d_{6}^{R 2 M}$ & 1.234568 & 1.234568 & 1.234568 & 1.234568 & 1.234568 & 1.234568 \\
\hline$h_{1}^{R 2 M}=\ldots=h_{6}^{R 2 M}$ & 1.234568 & 1.234568 & 1.234568 & 1.234568 & 1.234568 & 1.234568 \\
\hline
\end{tabular}

Indonesian J Elec Eng \& Comp Sci, Vol. 22, No. 2, May 2021 : 968 - 975 
Case 1 of the original model when the $B_{0}$ parameter and $P^{M}$ as a variable obtained, the value of $P^{M}=$ 1.234568 which means that when searching for an optimal solution, the amount of bandwidth consumption that was first used was $1.234568 \mathrm{kbps}$. The transfer value bandwidth from RB to RUE $P_{42}=250$ means the transfer of bandwidth from the fourth RB to the second RUE is $250 \mathrm{kbps}$. In Case 2 for $P_{51}=250.2898$ which means for bandwidth transfer from the fifth RB at the first RUE is $250.2898 \mathrm{kbps}$.

Next, for Case 1 of improved model, when $B_{0}$ as parameter and $P^{\mathrm{M}}$ as variable then $P^{\mathrm{M}}=1.234568$ which means that in seeking optimal value, the amount of first bandwidth consumption is $1.234568 \mathrm{kbps}$, Bandwidth transfer value from RB to RUE $P_{41}=222.5723$ which means that bandwidth transfer from fourth $\mathrm{RB}$ in first RUE is $222.5723 \mathrm{kbps}$.

\section{CONCLUSION}

Based on the improved C-RAN model, the optimal solution is found in case 1 , namely $B_{0}$ as a parameter and $P^{M}$ as a variable with price of IDR $1 / \mathrm{kbps}$, with initial bandwidth usage of $1.234568 \mathrm{kbps}$. Better solution was achieved when applying improved model compared to original model. This study discusses an improved C-RAN model on the efficiency of bandwidth consumption in internet pricing which was modified into two cases. The optimal results will then be compared based on the optimal solution obtained from each case. For further research, it is recommended to develop a model by calculating optimal results involving fair network traffic management based on flat fee, usage-based, and two-part tariff pricing strategies. These strategies is best strategies that have been chosen by users, now a days.

\section{ACKNOWLEDGEMENTS}

This research of this article was funded by DIPA of Public Service Agency of Universitas Sriwijaya 2019.

\section{REFERENCES}

[1] K. Petrova, "ISPs-pricing Internet access," in Beyond Boundaries. Proceedings of the 2003 GBATA International Conference, N. D. C.-N. Chao, Ed. Budapest, Hungary, pp. 1042-1051, 2003.

[2] Y. Wu, P. H. Hande, H. Kim, M. Chiang, and D. H. K. Tsang, "QoS-Revenue Tradeoff with Time-Constrained ISP Pricing," in 2010 IEEE 18th International Workshop on Quality of Service (IWQoS) 2010, doi: 10.1109/IWQoS.2010.5542744.

[3] S.-y. Wu, L. M. Hitt, P.-y. Chen, and G. Anandalingam, "Customized Bundle Pricing for Information Goods: A Nonlinear Mixed-Integer Programming Approach," Management Science, vol. 54, pp. 608-622, 2008, doi: $10.1287 / \mathrm{mnsc} .1070 .0812$

[4] L. Audah, Z. Sun, and H. Cruickshank, "QoS based Admission Control using Multipath Scheduler for IP over Satellite Networks," International Journal of Electrical and Computer Engineering (IJECE), vol. 7, pp. 2958-2969, 2017, doi: 10.11591/ijece.v7i6.pp2958-2969.

[5] D. Barth, K. Deschinkel, M. Diallo, and L. Echabbi, "Pricing, QoS and Utility models for the Internet," Rapport de recherche interne, 2004.

[6] C. Bouras and A. Sevasti, "Pricing QoS over transport networks," Internet Research, vol. 14, pp. 167-174, 2004, doi: $10.1108 / 10662240410530871$

[7] C. Bouras and A. Sevasti, "SLA-based QoS pricing in DiffServ networks," Computer Communications, vol. 27, pp. 1868-1880, 2004, doi: 10.1016/j.comcom.2004.06.010.

[8] J. Byun and S. Chatterjee, "A strategic pricing for quality of service (QoS) network business," in Proceedings of the Tenth Americas Conference on Information Systems, New York, pp. 2561-2572, 2004.

[9] N. Merayo, P. Pavon-Marino, J. C. Aguado, R. J. Durán, F. Burrull, and V. Bueno-Delgado, "Fair Bandwidth Allocation Algorithm for PONs Based on Network Utility Maximization," Journal of Optical Communications and Networking,, vol. 9, pp. 75-86, 2016, doi: 10.1364/JOCN.9.000075.

[10] T. Harks and T. Poschwatta, "Priority Pricing in Utility Fair Networks," in 13TH IEEE International Conference on Network Protocols (ICNP'05), 2005, doi: 10.1109/ICNP.2005.33.

[11] S. Sain and S. Herpers, "Profit Maximisation in Multi Service Networks-An Optimisation Model," in Proceedings of the 11th European Conference on Information Systems ECIS 2003, Naples, Italy 2003.

[12] Y. Bakos and E. Brynjolfsson, "Bundling information Goods: Pricing, Profits and efficiency," Management Science, vol. 45 pp. 1613-1630, 1999, doi: 10.1287/mnsc.45.12.1613.

[13] F. M. Puspita, K. Seman, and B. M. Taib, "The Improved Models of Internet Pricing Scheme of Multi Service Multi Link Networks with Various Capacity Links," in Advanced Computer and Communication Engineering Technology. vol. 315, doi: 10.1007/978-3-319-07674-4_80.

[14] K. Seman, F. M. Puspita, B. M. Taib, and Z. Shafii, "An improved optimization model of internet charging scheme in multi service networks," TELKOMNIKA (Telecommunication, Computing, Electronics and Control), vol. 10, pp. 592-598, 2012, doi: 10.12928/telkomnika.v10i3.842. 
[15] R. Sitepu, F. M. Puspita, E. Kurniadi, Yunita, and S. Apriliyani, "Mixed Integer Nonlinear Programming (MINLP)Based Bandwidth Utility Function On Internet Pricing Scheme With Monitoring And Marginal Cost," International Journal of Electrical and Computer Engineering (IJECE). vol. 9, pp. 1240-1248, 2019, doi: 10.11591/ijece.v9i2.pp.1240-1248.

[16] M. Jaloun and Z. Guennoun, "Mathematical Model for LTE System Dimensioning," Journal of Mobile Multimedia, vol. 9, pp. 303-318, 2014, doi: 10.1109/NGNS.2012.6656110.

[17] Y. Li, T. Zhou, Y. Yang, H. Hu, and M. Hamalainen, "Fair Downlink Traffic Management for Hybrid LAALTE/Wi-Fi Networks," IEEE Access, vol. 5, pp. 7031-7041, 2017, doi: 10.1109/ACCESS.2016.2642121.

[18] Indrawati, F. M. Puspita, S. Erlita, and I. Nadeak, "Analysis Model in the Cloud Optimization Consumption In Pricing the Internet Bandwidth," International Journal of Electrical and Computer Engineering (IJECE), vol. 8, 2018, doi: 10.11591/ijece.v8i6.pp4391-4397.

[19] H. Dai, Y. Huang, J. Wang, and L. Yang, "Resource Optimization in Heterogeneous Cloud Radio Access Networks," IEEE Communications Letters, vol. 22, pp. 494-497, 2018, doi: 10.1109/LCOMM.2017.2787676.

[20] I. Angri, M. Mahfoudi, A. Najid, and M. E. Bekkali, "Exponential MLWDF (EXP-MLWDF) Downlink Scheduling Algorithm Evaluated in LTE for High Mobility and Dense Area Scenario," International Journal of Electrical and Computer Engineering (IJECE), vol. 8, pp. 1618-1628, 2018, doi: 10.11591/ijece.v8i3.pp1618-1628.

[21] W. Ogryczak, H. Luss, M. Pióro, D. Nace, and A. Tomaszewski, "Fair optimization and networks: A survey," Journal of Applied Mathematics, vol. 2014, 2014, doi: 10.1155/2014/612018.

[22] P. Varade, A. Wabale, R. Yerram, and R. Jaiswal, "Throughput Maximization of Cognitive Radio Multi Relay Network with Interference Management," International Journal of Electrical and Computer Engineering (IJECE), vol. 8, pp. 2230-2238, 2018, doi: 10.11591/ijece.v8i4.pp2230-2238.

[23] S. Sudha and N. Ammasaigounden, "A modified approach for fair bandwidth allocation between TCP and UDP traffic in DiffServ network," in 2008 International Conference on Computer and Communication Engineering, IEEE, Kuala Lumpur, Malaysia 2008, doi: 10.1109/ICCCE.2008.4580713.

[24] M. Menth and N. Zeitler, "Activity-based congestion management for fair bandwidth sharing in trusted packet networks," in NOMS 2016 - 2016 IEEE/IFIP Network Operations and Management Symposium Istanbul, Turkey 2016, doi: 10.1109/NOMS.2016.7502817.

[25] C. Dou and S.-J. Jiang, "Fair scheduling of integrated IP and ATM based traffic in 3G mobile communication networks," in IEEE VTS 53rd Vehicular Technology Conference, Spring 2001 Proceedings (Cat. No.01CH37202). Rhodes, Greece, 2001, doi: 10.1109/VETECS.2001.944094.

[26] X. Huang, J. Wu, G. Sun, and J. Jing, "A New Fair Active Queue Management Algorithm," in 2009 International Conference on Future Networks, IEEE Bangkok, Thailand 2009, doi: 10.1109/ICFN.2009.29.

[27] J. Chung, M. Claypool, and R. Kinicki, "Stochastic Fair Traffic Management for Efficient and Robust IP Networking," in 2007 IEEE International Performance, Computing, and Communications Conference New Orleans, LA, USA 2007, doi: 10.1109/PCCC.2007.358878.

[28] E. Amaldi, A. Capone, S. Coniglio, and L. G. Gianoli, "Network optimization problems subject to max-min fair flow allocation," IEEE Communications Letters, vol. 17, no. 7, pp. 1463-1466, 2013, doi: 10.1109/LCOMM.2013.060513.130351.

[29] Indrawati, F. M. Puspita, S. Erlita, and I. Nadeak, "Optimasi Model Cloud Radio Access Network (CRAN) pada Efisiensi Konsumsi Bandwidth dalam Jaringan," in 3rd Annual Research Seminar on Computer Science and ICT, Universitas Sriwijaya, Palembang, 2017.

[30] M. Jiang and T. Mahmoodi, "Traffic Management in 5G Mobile Networks: Selfish Users and Fair Network," Transactions on Networks and Communications, vol. 4, 2016, doi: 10.14738/tnc.41.1447.

\section{BIOGRAPHIES OF AUTHORS}

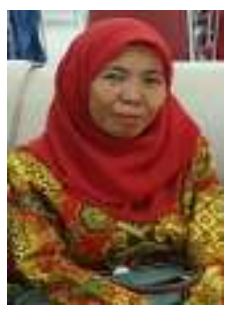

Indrawati received her S.Si degree in Mathematics from Sriwijaya University, South Sumatera, Indonesia in 1996. Then she received her M.Si of Actuarial Science in Bandung Institute of Technology in 2004. She has been a Mathematics Department member at Faculty mathematics and Natural Sciences Sriwijaya University South Sumatera Indonesia since 1998. Her research interests include inventory problems, dicrete optimization, applied linear algra, geometry and management of CRAN-Cloud networks.

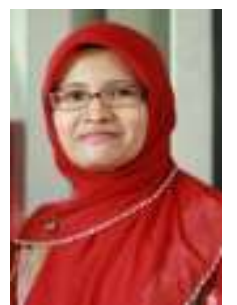

Fitri Maya Puspita received her S.Si degree in Mathematics from Sriwijaya University, South Sumatera, Indonesia in 1997. Then she received her M.Sc in Mathematics from Curtin University of Technology (CUT) Western Australia in 2004. She graduated from Faculty of Science and Technology Islamic Science University of Malaysia (USIM), Nilai, Negeri Sembilan Darul Khusus, Malaysia in 2015. She has been a Mathematics Department member at Faculty mathematics and Natural Sciences Sriwijaya University South Sumatera Indonesia since 1998. Her research interests include internet pricing scheme, mathematical programming of the networks and inventory problems.

Indonesian J Elec Eng \& Comp Sci, Vol. 22, No. 2, May 2021 : 968 - 975 


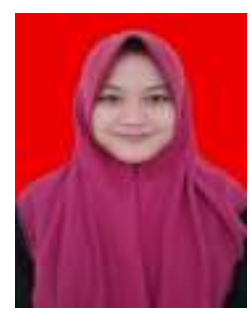

Desta Wahyuni currently receives her S.Si degree in Mathematics from Sriwijaya University, South Sumatera, Indonesia in early 2000. Her research interests include optimization problem and its application to C-RAN, cloud network and fair management in $5 \mathrm{G}$ networks.

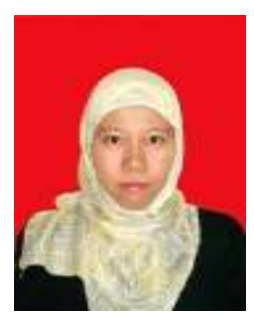

Evi Yuliza received her received her S.Si degree in Mathematics from Sriwijaya University, South Sumatera, Indonesia in 2000. Then she received M.Si in Mathematics in University of Gajah Mada, Indonesia in 2004. She has been a Mathematics Department member at Faculty mathematics and Natural Sciences Sriwijaya University South Sumatera Indonesia. Her research interest includes algrbra, analysis, discrete optimization. She is currently on her final stage of completing her P.hD program at Sriwijaya University.

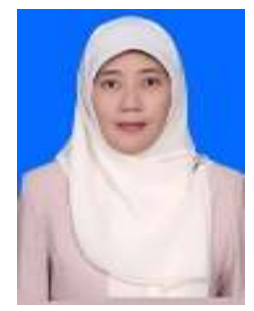

Oki Dwipurwani her received her S.Si degree in Statistics in Bogor Institute of Agriculture, in 1997. Then she received M.Si in Mathematics in Bogor Institute of Agriculture, Indonesia. She has been a Mathematics Department member at Faculty mathematics and Natural Sciences Sriwijaya University South Sumatera Indonesia 2000. Her research interests include Probability theory, Time Series, Sampling Technique, Multivariate analysis and currently intend to focus her interest of research on probabilistic inventory systems. 